\title{
STUDY ON THE ASSOCIATION OF SLC2A9 rs16890979 WITH GOUT IN 410 VIETNAMESE INDIVIDUALS
}

\author{
Nguyen Tran Minh Thang ${ }^{1,2}$, Nguyen Thy Ngoc ${ }^{1,3}$, Nguyen Thanh Nga $^{1}$, \\ Nong Van Hai ${ }^{1,4}$, Nguyen Thuy Duong, ${ }^{1,4 * *}$ \\ ${ }^{1}$ Institute of Genome Research, VAST, Vietnam \\ ${ }^{2}$ Pham Ngoc Thach University of Medicine, Hanoi, Vietnam \\ ${ }^{3}$ University of Science and Technology of Hanoi, VAST, Vietnam \\ ${ }^{4}$ Graduate University of Science and Technology, VAST, Vietnam
}

Received 29 September 2020, accepted 15 March 2021

\begin{abstract}
Gout is a common form of inflammatory arthritis caused by crystallization of acid uric in the joints. The development of gout is not only triggered by environmental factors but also by genetic variation of individuals. In this study, the association between the variation SLC2A9 rs16890979 and gout was investigated. Total DNA was extracted from 410 blood samples of 163 gout patients and 247 age-matched healthy controls. Genotypes of SLC2A9 rs16890979 were obtained using PCR-RFLP. Chi-Square test was used to test whether allele distribution of rs16890979 followed Hardy-Weinberg Equilibrium (HWE). Associations of the clinical characteristics between gout patient and control groups were assessed using Mann-Whitney U. Chi-Square test or Fisher's exact test was used to check four models (additive, recessive, dominant, co-dominant) for association of rs16890979 with gout. The obtained results showed that the allele distribution of SLC2A9 rs16890979 was in accordance with HWE (p > 0.05). Clinical characteristics such as triglyceride and creatinine were significantly different between gout patient and control groups. However, there was no association of rs16890979 with the risk of gout in Vietnamese population. Further study with a larger sample size should be implemented to confirm our results regarding the association of SLC2A9 rs16890979 with gout in the Vietnamese population. This study would help enrich the knowledge about the effects of hereditary factors on gout disease in the Vietnamese population.
\end{abstract}

Keywords: Gout, SLC2A9, rs16890979, PCR-RFLP, uric acid.

Citation: Nguyen Tran Minh Thang, Nguyen Thy Ngoc, Nguyen Thanh Nga, Nong Van Hai, Nguyen Thuy Duong, 2021. Study on the association of SLC2A9 rs16890979 with gout in 410 Vietnamese individuals. Academia Journal of Biology, 43(1): 129-136. https://doi.org/10.15625/2615-9023/15551

*Corresponding author email: tdnguyen@igr.ac.vn

(C2021 Vietnam Academy of Science and Technology (VAST) 


\section{INTRODUCTION}

In recent decades, the prevalence of gout has increased drastically in both developed and developing countries, including Vietnam. The rate of acquiring gout in $\mathrm{Ha}$ Noi, is $0.14 \%$ (Smith, 2010). Hyperuricemia ( $\geq 7 \mathrm{mg} / \mathrm{dl}$ ) leading to formations of monosodium urate (MSU) crystals in joints and soft tissues (Burns CM 2012) is the main cause of gout (Taniguchi, 2005). Gout patients are at high risks of other diseases, including heart and kidney diseases, obesity, blood lipid disorder, high blood pressure and glucose (Choi HK 2008, Emmerson 1998, Stamp, Chapman 2013, Takahashi S 1994). The metabolic syndromes (MetS) are characterized by several factors, notably high levels of triglyceride and creatinine (Chen et al., 2007, Ford 2005, Reynolds, He 2005). MetSs increase the risk of heart and vascular diseases, as well as type 2 diabetes. In gout patients, MetS acquiring rates are considerably high, being $30.1 \%-57 \%$, $36.8 \%$, $48.6 \%, 62.8 \%$, and $82 \%$ among Koreans, Taiwanese, Japanese, Americans and Mexicans, respectively (Choi et al., 2007, Inokuchi et al., 2010, Kuo et al., 2009, Rho et al., 2005, Vázquez-Mellado et al., 2004). Hence, EULAR (the European League Against Rheumatism and the British Society for Rheumatology) have proposed screening gout patients for risk factors of heart diseases caused by urate crystals (Jordan et al., 2007, Zhang et al., 2006). MetSs have also been proven to be closely related to the chronic kidney disease, which can be determined based on the estimated Glomerular Filtration Rate (eGFR) and blood creatinine level. In American populations, chronic kidney disease is 2.6 times more prevalent among patients with MetSs, while among Japanese, this is 1.54 times (Bhowmik, Tiwari 2008, Chen et al., 2007). Similarly, in Chinese populations, blood creatinine level is higher in chronic kidney patients than in individuals without MetSs (Chen et al., 2007).

Among risk factors for gout, hereditary factors play an important role. Genome-Wide Association Studies (GWAS) have revealed associations of polymorphisms in the gene SLC2A9 with blood uric acid level and gout (Dehghan et al., 2008, Voruganti et al., 2013). The gene SLC2A9 encodes the protein GLUT9, which is responsible for transport and reabsorption of uric acid in kidneys (Vitart et al., 2008). Studies among human populations in Framingham $(\mathrm{n}=7699)$ and Rotterdam ( $\mathrm{n}=4148)$ revealed that the polymorphism rs16890979, which changed Valine to Isoleucine (V253I) in the GLUT9, reduced blood acid uric level in both Caucasians and other populations. Particularly, the allele rs16890979A is related to reduced level of blood acid uric (Dehghan et al., 2008). In Vietnam, until now, this variation has not been investigated. This study was therefore conducted to determine the distribution of the variation in SLC2A9 rs16890979 and its relation with gout and other clinical characteristics, as well as the possibility of using this variation as a molecular marker in early detection of gout in Vietnamese population.

\section{MATERIALS AND METHODS}

A total of 410 subjects including 163 gout patients and 247 healthy controls were enrolled at Dai Phuoc General Clinic, Ho Chi Minh City, Vietnam during 2016-2017. Gout patients were diagnosed in accordance with the criteria of the American College of Rheumatology (Neogi et al., 2015).

\section{Total DNA extracted}

Total DNA was extracted using JET Whole Blood Genomic DNA purification Minikit \#K0781 of Thermo Fisher Scientific, America, following the manufacturer's protocol. Total DNA was diluted to $10 \mathrm{ng} / \mu \mathrm{L}$ with TE and kept at $-20{ }^{\circ} \mathrm{C}$ for later experiments. Total DNA concentration was determined using spectrophotometer Nanodrop 2000c (Thermo Scientific, Mỹ).

\section{Amplification of the region containing rs16890979}

The specific primer pair used to amplify the DNA fragment containing polymorphism rs16890979, 259 bp in length, was 
synthesized at Phu Sa company. The primer sequences were F: 5'TGAGCAAATCATGGCATCTC-3'; R: 5'ACCTCCT CTACCTCTTGGTTAA-3'.

Reaction components $(10 \mu$ l total volume) included $10 \mathrm{ng}$ DNA, $0.25 \mathrm{mmol}$ each dNTP (Thermo Fisher Scientific), 0.15 U Taq DNA polymerase (Thermo Fisher Scientific), 5 pmol primer (per each direction), Dream Taq Buffer (Thermo Fisher Scientific).

The PCR cycle was as follows: $94{ }^{\circ} \mathrm{C}$ in 4 minutes; 30 cycles of $94{ }^{\circ} \mathrm{C}$ in $15 \mathrm{~s}, 62^{\circ} \mathrm{C}$ in $15 \mathrm{~s}, 72{ }^{\circ} \mathrm{C}$ in $30 \mathrm{~s} ; 72{ }^{\circ} \mathrm{C}$ in 8 minutes; kept at $4{ }^{\circ} \mathrm{C}$.

\section{Genotyping of $S L C 2 A 9$ rs16890979 using RFLP}

The restriction enzyme HpaI (New England BioLabs) was used to digest the PCR product. Reaction components included $1 \mu 1$ of 10X Cutsmart ${ }^{\circledR}$ buffer, $3 \mu \mathrm{l}$ of PCR product, $0.1 \mu \mathrm{l}$ of $\mathrm{HpaI}$ and added water to $10 \mu \mathrm{l}$.

The restriction enzyme HpaI cut the PCR products containing allele $\mathrm{A}$ into DNA fragments of $239 \mathrm{bp}$ and $20 \mathrm{bp}$. In case of having the variant, the DNA of $259 \mathrm{bp}$ would not be cut. The genotypes of the SNP could be determined through the number and size of DNA bands after electrophoresis (Table 1 and Fig. 1).

Table 1. Number and size of DNA bands after digesting with enzyme for different genotypes

\begin{tabular}{|c|c|c|}
\hline Genotype & Number of DNA bands & Band length (bp) \\
\hline A/A & 1 & 259 \\
\hline G/G & 2 & 239,20 \\
\hline G/A & 3 & $259,239,20$ \\
\hline
\end{tabular}

\begin{tabular}{|c|c|c|c|c|c|c|c|}
\hline & $M$ & 1 & 2 & 3 & 4 & 5 & $\mathrm{~N}$ \\
\hline $300 \mathrm{bp}$ & 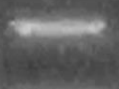 & 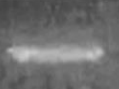 & $x_{x \rightarrow 3} 4$ & $=x$ & setis & -5 & \\
\hline $\mathrm{ob}$ & ens? & & 8 & & & & i \\
\hline
\end{tabular}

Figure 1. Image of HpaI-digested PCR products on agarose gel 2.5\%; M: Marker100 bp; 1: Homozygous AA (1 band with 259 bp); 2, 3: Heterozygous GA (2 bands, 259 bp and $239 \mathrm{bp}$ ); 4,5: Homozygous GG (1 band with $239 \mathrm{bp}$ ); N: Negative control
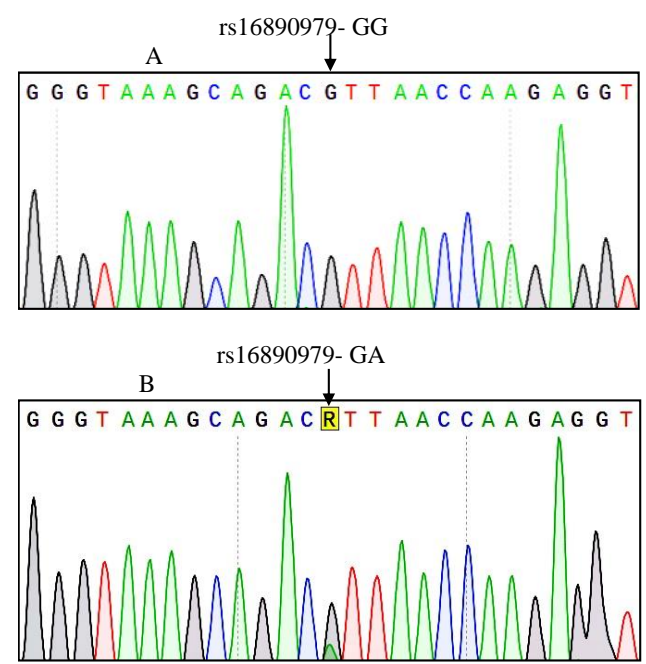

Figure 2. Genotyping using Sanger sequencing, A: Homozygous form GG;

B: Heterozygous form GA 
Nguyen Tran Minh Thang et al.

\section{Sequencing}

After genotyping using RFLP, $10 \%$ of the samples were randomly selected for sequencing using Sanger ABI PRISM 3500 Genetic Analyzer with the kit BigDye Terminator v3.1 (Applied Biosystems). Sequencing results were aligned against reference sequences on Gene Bank and analyzed using bioinformatic softwares Bioedit $v$ 7.2, BLAST, ClustalX and Sequence Scanner (Fig. 2).

\section{Statistical analysis}

The obtained data were analyzed using SPSS version 20. Chi-square and MannWhitney tests were used to assess the association between clinical characteristics and gout in study subjects. Fisher's Exact test and Chi-square were used to compare genotype ratios, allele ratios between the gout and control groups and calculate HardyWeinberg equilibrium. The association between variation rs16890979 in the gene
SLC2A9 and risk of gout was evaluated using Fisher's exact test. All tests were two-sided. $\mathrm{P}$-values of $\mathrm{p}<0.05$ were considered significant.

\section{RESULTS}

\section{Statistical analysis of clinical factors}

Among clinical factors of both groups, significant statistical differences between two groups have been found for both qualitative indices of hyperuricemia, stomach inflammation, and lipid disorder (Chi-square with $\mathrm{p}<0.05$ ), and quantitative ones, being uric acid, BMI, CRP, and triglyceride (MannWhitney with $p<0.05$ ) (Table 2). Both qualitative and quantitative values were higher in the gout group compared to the control group. Hyperuricemia was relatively high in gout patients $(92.6 \%)$ compared to $53 \%$ in the control group. Similarly, significant differences in uric acid and triglyceride between two groups were detected $(\mathrm{p}<0.001)$.

Table 2. Statistical analysis of clinical indices

\begin{tabular}{|l|c|c|c|c|}
\hline & $\begin{array}{c}\text { Control group } \\
(\mathrm{N}=247)\end{array}$ & $\begin{array}{c}\text { Gout group } \\
(\mathrm{N}=163)\end{array}$ & $\begin{array}{c}\text { Total } \\
(\mathrm{N}=410)\end{array}$ & P value \\
\hline Hyperuricemia-n (\%) & $131(53 \%)$ & $151(92.6 \%)$ & $282(68.8 \%)$ & $<0.001^{(1)}$ \\
\hline Stomach inflammation $-\mathrm{n}(\%)$ & $41(16.6 \%)$ & $50(30.7 \%)$ & $91(22.2 \%)$ & $0.001^{(1)}$ \\
\hline Lipid disorder-n $(\%)$ & $49(19.8 \%)$ & $64(39.3 \%)$ & $113(27.6 \%)$ & $<0.001^{(1)}$ \\
\hline Uric Acid $(\mathrm{mg} / \mathrm{dL}):$ mean \pm S.D & $7.17 \pm 1.60$ & $15.11 \pm 51.96$ & $10.33 \pm 32.95$ & $<0.001^{(2)}$ \\
\hline BMI $\left(\mathrm{kg} / \mathrm{m}^{2}\right):$ mean \pm S.D & $24.68 \pm 3.69$ & $25.30 \pm 3.31$ & $24.93 \pm 3.55$ & $0.037^{(2)}$ \\
\hline Triglyceride $(\mathrm{mg} / \mathrm{dL}):$ mean \pm S.D & $217.3 \pm 136.03$ & $275.57 \pm 234.30$ & $240.4 \pm 168.27$ & $<0.001^{(2)}$ \\
\hline CRP $(\mathrm{mg} / \mathrm{dL}):$ mean \pm S.D & $4.58 \pm 7.41$ & $10.20 \pm 67.44$ & $6.81 \pm 42.92$ & $0.004^{(2)}$ \\
\hline
\end{tabular}

Notes: BMI: Body Mass Index, CRP: C-reactive protein), n (\%): Number of individuals (percentage); ${ }^{(1)}$; $\mathrm{p}$-value by Chi-square test; ${ }^{(2)}$ : p-value by Mann-Whitney test.

\section{Assessing the association between polymorphism rs16890979 and gout}

Genotype distribution of rs16890979 followed Hardy-Weinberg principle (Chisquare test with $\mathrm{p}=0.956$ ) (Table 3 ).

Fisher's Exact and Chi-square tests were used to assess the association between rs16890979 (G>A) and gout (Table 4). In a dominant model, the genotype GG is dominant in both the control group and the gout group, being $96.4 \%$ and $98.2 \%$, respectively. The genotype GA is more common in the control group (3.6\%) than in the gout group $(1.8 \%)$. In both groups, no individuals carried the genotype AA. Allele $\mathrm{G}$ is highly prevalent at $99.1 \%$ in the gout group and $98.2 \%$ in the control group while allele A only appeared in $0.9 \%$ of the gout group and in $1.8 \%$ of the control group. No significant differences in genotype and allele were detected between the two groups. Hence, genotype and allele frequency of SNP rs16890979 (G>A) are not associated with risk of gout among the study subjects. 
Table 3. Polymorphism rs16890979 in the study population

\begin{tabular}{|c|c|c|c|c|c|c|c|}
\hline SNP_ID & Gene & Position $^{(*)}$ & $\begin{array}{c}\text { Mutation } \\
\text { type }\end{array}$ & $\begin{array}{c}\text { Reference/ } \\
\text { Alternate } \\
\text { allele }\end{array}$ & $\begin{array}{c}\text { MAF } \\
\text { among } \\
\text { control group }\end{array}$ & $\begin{array}{c}\text { MAF } \\
\text { among } \\
\text { gout group }\end{array}$ & $\begin{array}{c}\text { p value } \\
\text { for } \\
\text { HWE }\end{array}$ \\
\hline Rs16890979 & SLC2A9 & $4: 9920543$ & Missense & G/A & 0.019 & 0.009 & 0.956 \\
\hline
\end{tabular}

Notes: (*) Position in GRCh38.p10; (**) MAF: Minor Allele frequency.

Table 4. Correlation between SNP rs16890979 (SLC2A9) and gout trait

\begin{tabular}{|c|c|c|c|c|c|c|}
\hline SNP (Gene) & Model & Control group N=247 & Gout group N=163 & OR & $95 \%$ CI & P value \\
\hline$r s 16890979$ & \multicolumn{5}{|c|}{ dominant } & \\
\hline$($ SLC2A9) & GG & $238(96.4 \%)$ & $160(98.2 \%)$ & 1.00 & & \\
\hline & GA & $9(3.6 \%)$ & $3(1.8 \%)$ & 0.496 & $0.132-1.86$ & 0.289 \\
\hline & Alleles & & & & & \\
\hline & G & $485(98.2 \%)$ & $323(99.1 \%)$ & 1.00 & & \\
\hline & A & $9(1.8 \%)$ & $3(0.9 \%)$ & 0.5 & $0.087-2.027$ & 0.381 \\
\hline
\end{tabular}

Notes: n (\%): Number of individuals (percentage); OR: Odd ratio; 95\% CI: 95\% confidence interval.

In the gout group, triglyceride level is higher among individuals carrying the genotype $\mathrm{CC}$ than in those carrying CT. Meanwhile, creatinine level is lower in individuals carrying the genotype $\mathrm{CC}$. While these differences in blood indices between two genotypes of the same trait are considerably small, the p-values were considerably significant $(\mathrm{p}=0.007, \mathrm{p}=$ 0.046 for triglyceride and creatinine, respectively) (Table 5). This showed a correlation of the variation rs 16890979 with triglyceride and creatinine in the gout group.

Table 5. Correlation of rs 16890979 with the triglyceride and creatinine indices in blood of the study population

\begin{tabular}{|c|c|c|c|c|c|}
\hline \multirow{2}{*}{ SNP/Model } & \multirow{2}{*}{ Genotype } & \multicolumn{2}{|c|}{ Triglyceride } & \multicolumn{2}{c|}{ Creatinine } \\
\cline { 3 - 6 } & & Mean \pm SD & p-value & Mean \pm SD & p-value \\
\hline & & & 0.007 & & 0.046 \\
\hline$R s 16890979$ & CC & $275.57 \pm 203.30$ & & $1.11 \pm 0.31$ & \\
\hline Dominant model & CT & $263.10 \pm 172.03$ & & $1.14 \pm 0.37$ & \\
\hline
\end{tabular}

\section{DISCUSSION}

Several recent studies have shown the effects of hereditary factors on uric acid excretion through the kidneys. Polymorphisms in the urate transport gene SLC2A9 have been shown to be a gout risk factor among many human populations such as Caucasians (Dehghan et al., 2008, Moffatt et al., 2009), Maorisand Polynesians (Moffatt et al., 2009), Han Chinese and in Solomon island (Tu et al., 2009).

In 2015, Meng et al. showed that rs16890979 or V253I could play a role in reducing risk of gout. However, among the study subjects, we have found no associations between rs16890979 and the risk of gout. This may be due to differences in genetic background of geographically separated populations. Besides, study by Dehghan et al. in African American populations showed different distributions of rs16890979 among populations of different ethnic origins (Dehghan et al., 2008).

The protein GLUT9 encoded by the gene $S L C 2 A 9$ expresses mainly in kidneys and is responsible for maintaining urate level in blood and the excretion of uric acid through urine (Dinour et al., 2010, Preitner et al., 2009). Polymorphisms in SLC2A9 have been shown to be correlated with high uric acid level in blood (Brandstätter et al., 2008, Dehghan et al., 2008, Döring 2008, Voruganti 
et al., 2013). Population study on 541 individuals from Sardinia revealed the association between uric acid and rs16890979 with a p-value of 0.02 (Li S et al., 2007).

In our study, while hyperuricemia is prevalent among 163 gout patients $(92.6 \%)$, no associations between rs16890979 and uric acid level as well as hyperuricemia have been found (p-values of 0.215 and 0.622 , respectively). However, the statistical relation between rs16890979 and triglyceride or creatinine is significant. Both triglyceride and creatinine indices were proven to be related to kidney functions (Voruganti et al., 2013, Zubovic et al., 2016). Research by Voruganti et al. showed the relation between $S L C 2 A 9$ and kidney functions through creatinine level or eGFR (Voruganti et al., 2013). A high creatinine level is a sign of reduced glomerular filtration rate, or kidney damages caused by other diseases such as high blood pressure or vascular disease (Wannamethee et al., 1997). Zubovic revealed the correlation between triglyceride and chronic kidney disease through each stage of more than 150 individuals in Bosnia and Herzegovina. The triglyceride level started to increase in the beginning stage and peaked at stage IV and $\mathrm{V}$ of chronic kidney disease (Zubovic et al., 2016). A recent study showed high triglyceride level among chronic kidney disease patients, possibly leading to artery diseases (Keane et al., 2011, Ritz, Wanner 2008).

Results from our study provide data for later studies on the effects of the variation rs16890979 in the gene SLC2A9 on several metabolic disorder among a Vietnamese population.

\section{CONCLUSION}

In this study, we analyzed the correlation of the variant rs16890979 in the gene SLC2A9 with gout and other clinical characteristics. Results revealed that in Vietnamese population, rs 16890979 is not associated with gout but with triglyceride and creatinine in blood. The results need to be confirmed with a larger sample size from different areas of Vietnam. This study can contribute to future research on the relationship between the gene SLC2A9 and gout, providing the basis for gout diagnosis and treatment among Vietnamese population.

Acknowledgements: This study was conducted with funding from Vietnam Academy of Science and Technology under project NCVCC 40.01/20-20 and with support from Institute of Genome Research.

\section{REFRENCES}

Bhowmik D., Tiwari S. C., 2008. Metabolic syndrome and chronic kidney disease. Indian Journal of Nephrology, 18(1): 1-4.

Brandstätter A., Kiechl S., Kollerits B., Hunt S. C., Heid I. M., Coassin S., Willeit J., Adams T. D., Illig T., Hopkins P. N., Kronenberg F., 2008. Sex-Specific Association of the Putative Fructose Transporter SLC2A9 Variants With Uric Acid Levels Is Modified by BMI. Diabetes Care, 31(8): 1662-1667.

Burns C.M. W., 2012. Disorders of purine and pyramidine metabolism. McGraw-Hill, New York, USA.

Chen J., Gu D., Chen C. S., Wu X., Hamm L. L., Muntner P., Batuman V., Lee C. H., Whelton P. K., He J., 2007. Association between the metabolic syndrome and chronic kidney disease in Chinese adults. Nephrology Dialysis Transplantation, 22(4): 1100-1106.

Choi H. K., Krishnan E., 2008. Gout and the risk of type 2 diabetes among men with a high cardiovascular risk profile. Rheumatology, 47(10): 1567-1570.

Choi H. K., Ford E.S., Li C., Curhan G., 2007. Prevalence of the metabolic syndrome in patients with gout: the Third National Health and Nutrition Examination Survey. Arthritis Care \& Research: Official Journal of the American College of Rheumatology, 57(1): 109-115.

Dehghan A., Köttgen A., Yang Q., Hwang S. J., Kao W., Rivadeneira F., Boerwinkle E., Levy D., Hofman A., Astor B.C., 
Benjamin E. J., Van Duijn C. M., Witteman J. C., Coresh J., Fox C. S., 2008. Association of three genetic loci with uric acid concentration and risk of gout: a genome-wide association study. The Lancet, 372(9654): 1953-1961.

Dinour D., Gray N. K., Campbell S., Shu X., Sawyer L., Richardson W., Rechavi G., Amariglio N., Ganon L., Sela B. A., Bahat H., Goldman M., Weissgarten J., Millar M. R., Wright A. F., Holtzman E. J., 2010. Homozygous SLC2A9 Mutations Cause Severe Renal Hypouricemia. Journal of the American Society of Nephrology, 21(1): 64-72.

Döring A., Gieger D., Christian T., Mehta A., Divya C., Gohlke D., Henning T., Prokisch L., Holger H., Coassin D., Stefan D., 2008. SLC2A9 influences uric acid concentrations with pronounced sexspecific effects. Nature Genetics, 40(4): 330-335.

Emmerson B., 1998. Hyperlipidaemia in hyperuricaemia and gout. Annals of the Rheumatic Diseases, 57(9): 509-510.

Ford E. S., 2005. Risks for all-cause mortality, cardiovascular disease, and diabetes associated with the metabolic syndrome: a summary of the evidence. Diabetes care, 28(7): 1769-1778.

Hollis-Moffatt J. E., Xu X., Dalbeth N., Merriman M. E., Topless R., Waddell C., Gow P. J., Harrison A. A., Highton J., Jones P. B., 2009. Role of the urate transporter SLC2A9 gene in susceptibility to gout in New Zealand Māori, Pacific Island, and Caucasian case-control sample sets. Arthritis \& Rheumatism: Official Journal of the American College of Rheumatology, 60(11): 3485-3492.

Inokuchi T., Tsutsumi Z., Takahashi S., Ka T., Moriwaki Y., Yamamoto T., 2010. Increased frequency of metabolic syndrome and its individual metabolic abnormalities in Japanese patients with primary gout. Journal of Clinical Rheumatology, 16(3): 109-112.
Jordan K. M., Cameron J. S., Snaith M., Zhang W., Doherty M., Seckl J., Hingorani A., Jaques R., Nuki G., 2007. British Society for Rheumatology and British Health Professionals in Rheumatology guideline for the management of gout. Rheumatology, 46(8): 1372-1374.

Keane W. F., Tomassini J. E., Neff D. R., 2011. Lipid abnormalities in patients with chronic kidney disease. Hemodialysis, 36(2): 135-142.

Kuo C. F., See L. C., Luo S. F., Ko Y. S., Lin Y. S., Hwang J. S., Lin C. M., Chen H. W., Yu K. H., 2009. Gout: an independent risk factor for all-cause and cardiovascular mortality. Rheumatology, 49(1): 141-146.

Li S. S., Maschio A., Busonero F., Usala G., Mulas A., 2007. The GLUT9 gene is associated with serum uric acid levels in Sardinia and Chianti cohorts. PLoS Genet, 3(11): 194-197.

Meng Q., Yue J., Shang M., Shan Q., Qi J., Mao Z., Li J., Zhang F., Wang B., Zhao T., Wang W., 2015. Correlation of GLUT9 Polymorphisms With Gout Risk. Medicine (Baltimore), 94(44): e1742. https://doi.org/10.1097/MD.00000000000 01742

Neogi T., Jansen T. L., Dalbeth N., Fransen J., Schumacher H. R., Berendsen D., Brown M., Choi H., Edwards N. L., Janssens H. J., 2015. Gout classification criteria: An American college of Rheumatology European league against rheumatism collaborative initiative. Arthritis Rheumatol, 67(5): 2557-2568.

Preitner F., Bonny O., Laverrière A., Rotman S., Firsov D., Da C. A., Metref S., Thorens B., 2009. GLUT9 is a major regulator of urate homeostasis and its genetic inactivation induces hyperuricosuria and urate nephropathy. Proceedings of the National Academy of Sciences of the United States of America, 106(36): 15501-15506. 
Reynolds K., He J., 2005. Epidemiology of the metabolic syndrome. The American journal of the medical sciences, 330(6): 273-279.

Rho Y. H., Choi S.J., Lee Y.H., Ji J.D., Choi K.M., Baik S.H., Chung S. H., Kim C. G., Choe J. Y., Lee S. W., 2005. The prevalence of metabolic syndrome in patients with gout: a multicenter study. Journal of Korean medical science, 20(6): 1029-1033.

Ritz E., Wanner C., 2008. Lipid abnormalities and cardiovascular risk in renal disease. Journal of the American Society of Nephrology, 19(6): 1065-1070.

Smith E. U., 2010. Epidemiology of gout: an update. Best Pract Res Clin Rheumatol, 24(6): 811-827.

Stamp L. K., Chapman P. T., 2013. Gout and its comorbidities: implications for therapy. Rheumatology, 52(1): 34-44.

Takahashi S. Y., Moriwaki Y., Tsutsumi Z., Higashino K., 1994. Impaired lipoprotein metabolism in patients with primary gout influence of alcohol intake and body weight. Br J Rheumatol, 33(8): 731-734.

Taniguchi A. U., Yamanaka M., Yamanaka H., Hosoyamada M., Endou H., Kamatani N., 2005. A common mutation in an organic anion transporter gene, SLC22A12, is a suppressing factor for the development of gout. Arthritis Rheum, 52(2): 2576-2577.

Tu H. P., Chen C. J., Tovosia S., Ko A. S., Lee C. H., Ou T. T., Lin G. T., Chang S. J., Chiang S. L., Chiang H. C., 2009. Associations of a nonsynonymous variant in SLC2A9 with gouty arthritis and uric acid levels in Han Chinese and Solomon Islanders. Annals of the rheumatic diseases, 43(2): 357-359.

Vázquez M. J., García C. G., Medrano G., Ornelas M., Alcocer L., Marquez A.,
Burgos V. R., 2004. Metabolic syndrome and ischemic heart disease in gout. Journal of Clinical Rheumatology, 10(3): 105-109.

Vitart V., Rudan I., Hayward C., Gray N. K., Floyd J., Palmer C. N., Knott S. A., Kolcic I., Polasek O., Graessler J., Wilson J. F., Marinaki A., Riches P. L., Shu X., Janicijevic B., Smolej N., Gorgoni B., Morgan J., Campbell S., Biloglav Z., Barac L., Pericic M., Klaric I. M., Zgaga L., Skaric J. T., Wild S. H., Richardson W. A., Hohenstein P., Kimber C. H., Tenesa A., Donnelly L. A., Fairbanks L. D., Aringer M., McKeigue P. M., Ralston S. H., Morris A. D., Rudan P., Hastie N. D., Campbell H., Wright A. F., 2008. SLC2A9 is a newly identified urate transporter influencing serum urate concentration, urate excretion and gout. Nature Genetics, 42(2): 437-441.

Voruganti V. S., Franceschini N., Haack K., Laston S., Maccluer J. W., Umans J. G., Comuzzie A. G., North K. E., Cole S. A., 2013. Replication of the effect of SLC2A9 genetic variation on serum uric acid levels in American Indians. European Journal Of Human Genetics, 22(9): 138-141.

Wannamethee S. G., Shaper A. G., Perry I. J., 1997. Serum Creatinine Concentration and Risk of Cardiovascular Disease. A Possible Marker for Increased Risk of Stroke, 28(3): 557-563.

Zhang W., Doherty M., Pascual E., Bardin T., Barskova V., Conaghan P., Gerster J., Jacobs J., Leeb B., Lioté F., 2006. EULAR evidence based recommendations for gout. Ann Rheum Dis, 65(1): 1301-1311.

Zubovic S. V., Kristic S., Prevljak S., Pasic I. S., 2016. Chronic Kidney Disease and Lipid Disorders. Medical Archives, 70(3): 191-192. 